\title{
LEIOMIOMA DE ESCROTO: APORTACIÓN DE UN CASO
}

\author{
J.I. JIMÉNEZ ARISTU, M.Á. PINÓS PAUL, Á. DE PABLO CÁRDENAS, \\ J. JIMÉNEZ CALVO, F. LOZANO URUÑUELA, C. SARMIENTO GÓMEZ,
} A. SANTIAGO GONZÁLEZ DE GARIBAY, M. MONTES DÍAZ*

Servicio de Urología. *Servicio de Anatomía Patológica. Hospital Virgen del Camino. Pamplona. Navarra.

Actas Urol Esp. 27 (10): 822-824, 2003

\section{RESUMEN}

LEIOMIOMA DE ESCROTO: APORTACIÓN DE UN CASO

El leiomioma escrotal es un tumor raro de comportamiento benigno, asintomático, originado en el músculo dartos y cuyo tratamiento de elección es quirúrgico.

Presentamos un nuevo caso en un paciente varón de 68 años con una masa escrotal de 10 años de evolución que, tras ser extirpada, el diagnóstico anatomopatológico fue de leiomioma.

PALABRAS CLAVE: Leiomioma escrotal. Tumor mesenquimal benigno.

\section{ABSTRACT}

LEIOMYOMA OF SCROTUM: CONTRIBUTION OF ONE CASE

Scrotal leiomyoma is a benign rare tumour, asymptomatic, which origin is the dartos muscle and the election treatment is surgical.

We report a new case in a 68-year-old patient with a 10 years history of a scrotal tumour and anatomopathological diagnostic post surgery was leiomyoma.

KEY WORDS: Scrotal leiomyoma. Benign mesenchymal tumor.

$L^{2}$ os genitales externos son el asiento de numerosas lesiones tumorales, entre las que se encuentra el leiomioma escrotal o dartoleiomioma que es un tumor de origen mesenquimal compuesto de fibras musculares lisas originarias del músculo dartos, asintomático en la mayor parte de los casos y de comportamiento benigno. Pese a ser descrito por primera vez en 1858 por Förster sólo se han publicado cerca de 45 casos $^{1-}$ ${ }^{6}$, lo que nos da idea de la poca frecuencia de este tumor. Presentamos un nuevo caso de leiomioma escrotal.

\section{CASO CLÍNICO}

Paciente varón de 68 años, sin antecedentes personales de interés, que consulta por presentar un sindrome prostático leve de dos años de evo- lución con un IPSS de 10 y PSA: 0,91. A la exploración física destaca un tacto rectal encontrando un adenoma grado 1, y una masa en hemiescroto derecho de $2 \mathrm{~cm}$ lisa, dura, no adherida a planos profundos, blanquecina e indolora a la exploración. El paciente refiere más de 10 años de evolución y demanda cirugía aduciendo problemas estéticos.

Se realiza exéresis de la masa bajo anestesia local sin incidencias. Macroscópicamente la masa presenta coloración blanquecina y consistencia firme con un tamaño de 1,7 cm, la superficie de corte muestra una lesión sólida, amarillenta de aspecto arremolinado.

Microscópicamente se describe una neoformación mesenquimal relativamente bien delimitada, no encapsulada, constituida por haces de células 
de estirpe muscular lisa que muestra marcada positividad citoplasmática con actina, desmina y focal con CD 68. No se observa atipia citológica. La actividad mitótica es muy baja (0,5 mitosis por 50 HPF), no observándose áreas de hemorragia ni necrosis.

El diagnóstico fue de leiomioma escrotal. Tras dos años de evolución no hay evidencia de recidiva local.

\section{COMENTARIO}

Los leiomiomas cutáneos se clasifican como piloleiomiomas (los más frecuentes), angioleiomiomas, leiomiomas genito-areolares y leiomiomas con componentes mixtos adicionales ${ }^{1,6,10}$. Los piloleiomiomas se originan del músculo pilar arrector del folículo piloso, con frecuencia multifocales, desarrollándose entre la $2^{\mathrm{a}}$ y $3^{\mathrm{a}}$ década de la vida. Se han descrito formas familiareshereditarias y no hereditarias. Clínicamente pueden presentar dolor por compresión nerviosa o por contracción muscular, localizándose con frecuencia en zonas de extensión, tronco y cara $^{1,2,4,6}$. Los angioleiomiomas, frecuentes en la $5^{\underline{a}}$ y $6^{\underline{a}}$ décadas, surgen de la capa media muscular de los vasos subcutáneos de la zona distal de las extremidades siendo solitarios y dolorosos $(50 \%)^{1,2,6}$. Los leiomiomas genito-areolares son tumores raros, solitarios e indoloros que se localizan por orden de frecuencia en vulva, escroto y areola $^{1,6}$ (Fig. 1).

Los leiomiomas escrotales o dartoleiomiomas son tumores solitarios originados en las fibras musculares lisas del $\operatorname{dartos}^{8-10}$. Generalmente

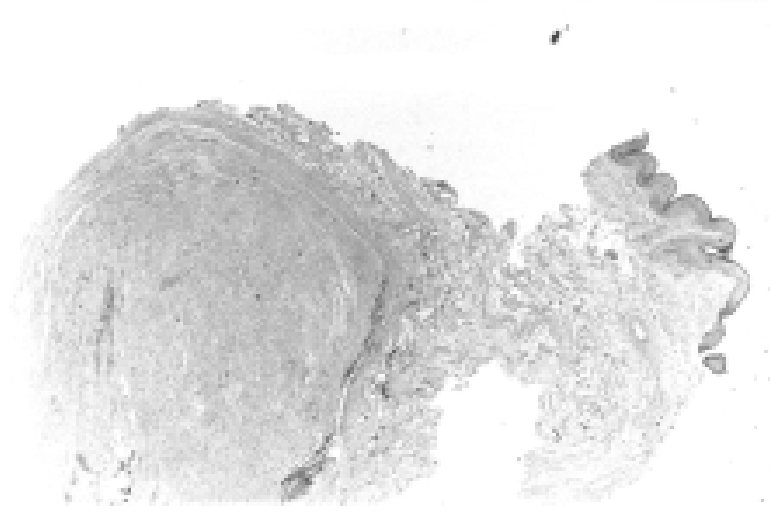

FIGURA 1: Escroto (piel y tejido celular subcutáneo) con una tumoración en profundidad nodular y bien delimitada. HE. son nódulos firmes, no adheridos a planos profundos, indoloros y raramente ulcerados ${ }^{1,3}$. Se han descrito formas pediculadas y un caso bilateral $^{2}$. Su tamaño oscila desde 1 a $8 \mathrm{~cm}$ y se localizan más frecuentemente en el escroto que en el pene, glande o prepucio ${ }^{7}$.

Debido a su carácter asintomático y crecimiento lento (se ha descrito un caso con 30 años de evolución) suelen ser un hallazgo en la exploración física de los pacientes aunque puede ser motivo de consulta por motivos estéticos ${ }^{1,2}$. Pueden realizarse pruebas complementarias como una radiografía simple, para descartar calcificaciones, o una ecografía para ver la dependencia del teste o la naturaleza sólida o quística de la masa ${ }^{6}$ (Fig. 2).

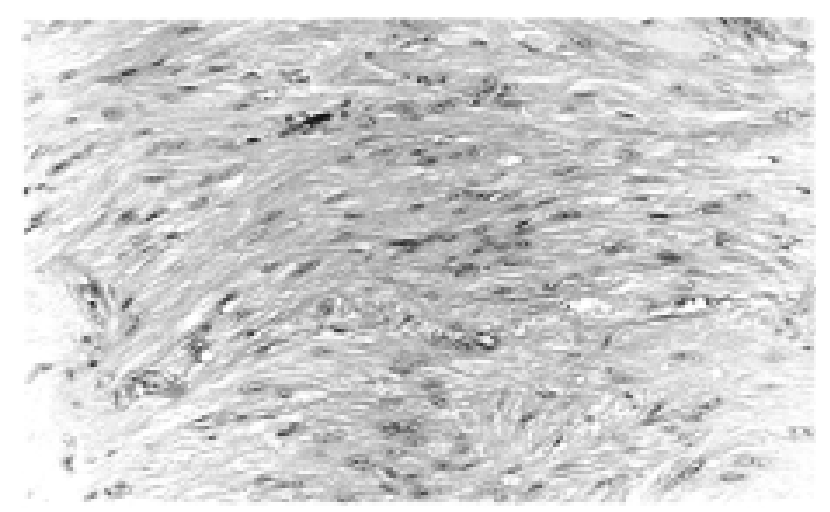

FIGURA 2: Detalle. Haces celulares fusiformes sin atipia citológica ni actividad mitótica. HE.

El diagnóstico es anatomopatológico, encontrándose una tumoración nodular, bien delimitada, generalmente por una pseudocápsula, de coloración blanco-amarillenta y aspecto fibrilar al corte $^{3}$. Al microscopio se observan haces celulares que se tiñen con hematoxilina-eosina, escasa o nula actividad mitótica celular y ocasional aparición de pleomorfismo celular. Muestran un patrón inmunohistoquímico característico de músculo liso con positividad a actina específica de músculo liso y a desmina ${ }^{1}$ (Fig. 3).

El diagnóstico diferencial se debe realizar con otros tumores benignos, como el quiste de inclusión dermal, el más frecuente, los quistes sebáceos y otros tumores mesenquimatosos benignos como los neurofibromas y neurilemomas ${ }^{1,6,10}$.

El tratamiento es quirúrgico, generalmente con anestesia local, realizando exéresis simple de 


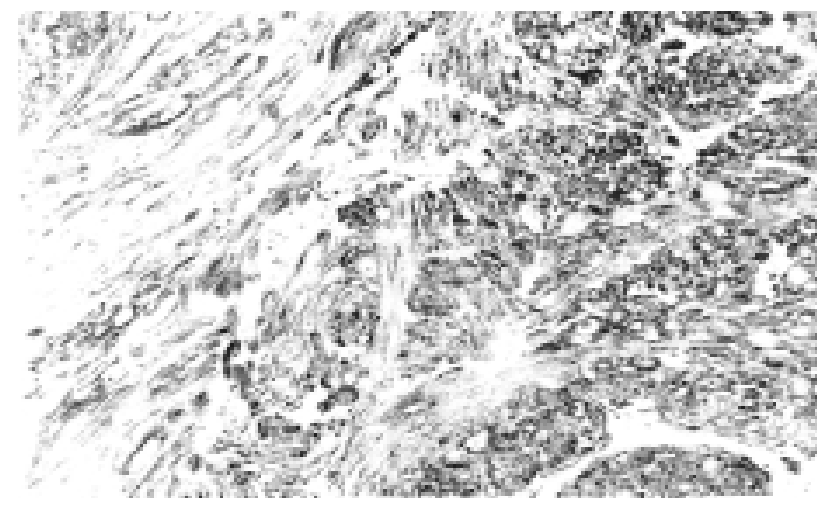

FIGURA 3: Células tumorales teñidas intensamente con desmina.

la masa no siendo necesario márgenes en la escisión, exceptuando casos con bordes mal defini$\operatorname{dos}^{3,4,6}$. Tanto la historia natural como la evolución del tumor tras cirugía es excelente, no habiéndose descrito ni recidivas ni progresión a leiomiosarcoma ${ }^{7}$.

\section{REFERENCIAS}

1. SLONE S, O`CONOR D.: Scrotal leiomyomas with bizarre nuclei: a report of three cases. Mod Patol 1998 mar; 11 (3): 282-287.

2. DAS AK, BOLICK D, LITTLE NA, WALTER PJ.: Pedunculated scrotal mass: leiomyoma of scrotum. Urology 1992 apr; 39 (4): 376-379.
3. PALACIOS P, FITER L, REDADERA J, NISTAL M, MARTÍNEZ PIÑEIRO JA.: Leiomioma de escroto: presentación de dos casos. Arch Esp de Urol 1987; 40 (1): 45-47.

4. RODRÍGUEZ-PARETS JO, SILVA ABUIN J, ABAD HERNÁNDEZ M y cols.: Leiomioma atípico de escroto. A propósito de un caso. Actas Urol Esp 1998 jul-agosto; 22 (7): 613-615.

5. WOLF DI.: Solitary nodule of the scrotum. Leiomyoma. Arch Dermatol 1989 mar; 125 (3): 418-9, 422.

6. SÁNCHEZ MERINO SC, GÓMEZ CISNEROS A, FERNÁNDEZ-FLORES L y cols.: Leiomioma de escroto. Actas Urol Esp 2001 mar; 25 (3): 233-236.

7. PEYRÍ E, ARANGO O, ÁLVAREZ-VIJANDER R, editores: Leiomioma dartósico del prepucio. En: Lesiones tumorales cutáneas de los genitales masculinos. Barcelona. Elfar, S.A 1999: 27.

8. ARMIJO M, CAMACHO F, editores: Tumores benignos de la dermis e hipodermis. En: Dermatología $2^{\mathrm{a}}$ ed. Madrid. Ediciones CEA 1988: 21 (1): 380-381.

9. IRANZO FERNÁNDEZ P y cols.: Lesiones cutáneas de la región inguino-escrotal. Urol Integr Invest 2002; 7 (1): 55-69.

10. ARANGO O.: Lesiones tumorales. En: Enfermedades cutáneas del aparato genital masculino. Peyrí E, Álvarez-Vijande R, Arango O, editores. Ed. ENE Ediciones. Madrid 1996: 191-193.

Dr. J.I. Jiménez Aristu

C/ Amaya, 40 - 4ํㅡㅁ Dcha

31004 Pamplona (Navarra)

(Trabajo recibido el 29 enero de 2003) 